\title{
ANÁLISE COMPARATIVA ENTRE CONCRETO CONVENCIONAL E REFORÇADO COM FIBRAS ATRAVÉS DE ENSAIOS ULTRASSÔNICOS
}

\author{
VICTOR IVAN DAL BOSCO \\ Acadêmico Engenharia Civil \\ LEME/UFRGS \\ RS; Brasil \\ victordalbosco@outlook.com
}

\author{
ALEXANDRE LORENZI \\ Engenheiro Civil \\ LEME/UFRGS \\ RS; Brasil \\ alexandre.lorenzi@ufrgs.br
}

\author{
LUIZ CARLOS P. SILVA FILHO \\ Engenheiro Civil \\ LEME/UFRGS \\ RS; Brasil \\ lcarlos66@gmail.com
}

\section{RESUMO}

Diferentes materiais vêm sendo adicionados ao concreto a fim de melhorar o seu comportamento, contribuindo assim para a evolução tecnológica desse composto. Entre eles, fibras de aço e de polipropileno são utilizados em diversas situações onde são necessárias fortalecer características em situações que o concreto possui baixo desempenho. Todavia, necessitam-se ferramentas para averiguar este incremento de desempenho. O ensaio de velocidade de propagação do pulso ultrassônico (VPU) é uma ferramenta auxiliar para a análise, visto que os resultados do ensaio podem ser correlacionado com a densidade do material. O objetivo deste trabalho é a realização de uma análise comparativa entre concretos convencionais, concretos reforçados com fibras de aço e concretos reforçados com fibras de polipropileno através do ensaio de VPU. Buscou-se neste estudo averiguar se o comportamento da VPU no concreto com adição de fibras será impactado da mesma forma que a resistência à compressão. Buscando atingir este objetivo foram confeccionados blocos de concreto convencional de traço 1:2,9:3,6; fator água/cimento de 0,66 e um fck estimado em $25 \mathrm{MPa}$. Os blocos foram moldados de cinco modos distintos: sem adição de fibras, com adição de $0,5 \%$ de fibras de aço, com adição de $0,5 \%$ de fibras de polipropileno, com adição de $1 \%$ de fibras de aço e com adição de $1 \%$ de fibras de polipropileno. O presente trabalho contém os resultados de um estudo realizado para determinar se a técnica de VPU é sensível ao uso de fibras no concreto e pode ser utilizada como ferramenta para estimar a qualidade do concreto com fibras. Os resultados obtidos indicaram que a VPU é sensível à utilização de fibras no concreto e pode ser utilizada para esta finalidade.

Palavras-chave: Concreto, Fibras, Ensaio Ultrassônico.

\begin{abstract}
Different materials have been added to concrete in order to improve the concrete behavior and contributing to the technological evolution. Among them, steel and polypropylene fibers are used in various situations where it is necessary to strengthen characteristics where concrete has low performance. The ultrasonic tests (UT) are used as a tool for the analysis since the test can be correlated to the material density. The aim of this work is to compare conventional concretes, steel fiber reinforced concrete and polypropylene fiber reinforced concrete through the UT. This study verify if the UT in concrete with fiber addition will be increased in the same way as compressive strength. In order to achieve this goal, conventional concrete blocks with concrete admixture by $1: 2.9: 3.6$; a water/cement factor of 0.66 and an fck of $25 \mathrm{MPa}$ were made. The blocks were molded in five different ways: no fiber addition, $0.5 \%$ steel fiber addition, $0.5 \%$ polypropylene fiber addition, $1 \%$ steel fiber addition and $1 \%$ polypropylene fibers addition. The present work contains the results to determine if the UT is sensitive to the use of fibers in concrete and can be used as a tool to estimate the quality of fiber concrete. The results indicated that the UT is sensitive to the use of fibers in concrete and can be used for this purpose.
\end{abstract}

Keywords: Concrete, Fiber, Ultrasonic Tests. 


\section{INTRODUÇÃO}

O concreto é um material largamente empregado na construção civil, devido às suas características de moldagem e resistência. Devido ao fato de ser o elemento estrutural mais utilizado no mundo e constituir parte fundamental dos mais variados projetos de engenharia necessitam-se de ferramentas de controle e análise do estado de deterioração e segurança das estruturas.

As características do concreto proporcionam a qualidade de ser um material de grande capacidade a esforços de compressão, no entanto seu comportamento em esforços de tração e flexão não segue a mesma tendência. Em virtude de ser um material amplamente utilizado, o concreto se torna foco de inúmeras pesquisas que permitem a evolução do composto.

De acordo com Medeiros (2012) os concretos com adição de fibras podem ser definidos como materiais compósitos, ou seja, materiais constituídos de, pelo menos, duas fases distintas. O próprio concreto já pode ser considerado um material compósito. Entretanto, consideram-se como fases principais do concreto com fibras, o próprio concreto (matriz) e as fibras, que podem ser produzidas de diferentes materiais: aço, vidro, nylon, polipropileno e outros.

A adição de fibras na mistura é uma alternativa encontrada para atuar em determinadas situacoes que se faz necessario algum incremento das propriedades do concreto. O compósito constituído de concreto e fibras amplia sua empregabilidade, visto que as fibras podem ser de diferentes tipos, como aço, polipropileno, carbono, vidro, nylon, cada uma com propriedades e formas distintas. As fibras inseridas na matriz de concreto retardam o aparecimento de fissuras aumentando a tenacidade do composto. As fibras de aço já estão bastante difundidas, sendo bastante utilizadas na fabricação de pavimentos e pisos industriais (Guimaraes, 2015). A NBR 15530 (2013) determina e classifica os diferentes tipos fibras de aço.

A padronização e aperfeiçoamento de técnicas e o desenvolvimento de métodos que possam avaliar a qualidade dos elementos fabricados com concretos reforçados com fibras são fundamentais. Dentre os ensaios utilizados para avaliar o concreto, o ensaio de resistência à compressão axial normatizado pela NBR 5739 (2007) é comumentemente utilizado para avaliar a resistência característica do concreto, porém quando há a adição de fibras outros parâmetros devem ser levados em consideração e ensaios complementares devem ser realizados.

\section{ENSAIO ULTRASSÔNICO}

Os métodos de ensaio ultrassônico aliam flexibilidade, baixo custo e boa capacidade de fornecimento de informações sobre o concreto. O método é baseado na determinação longitudinal da velocidade do pulso ultrassônico, e é um método bastante utilizado de Ensaios Não Destrutivos para avaliação do concreto devido a sua eficácia, simplicidade de aplicação e também pelo seu custo.

O ensaio de VPU para análise do concreto é um método de END, de fácil execução. A metodologia de aplicação da VPU se baseia no fato de que o tempo de propagação dos pulsos ultrassônicos é influenciado pela qualidade do concreto e expressa a densidade do material, característica que está diretamente correlacionada com as propriedades mecânicas. Desta maneira, a medida da VPU teoricamente permitiria, além de estabelecer a relação existente entre a qualidade do concreto e a VPU, correlacionar a velocidade de pulso com a resistência à compressão.

O ensaio é normatizado pela NBR 8802 (2013) e consiste num aparelho que emite uma onda através do concreto e registra o tempo necessário para isso. Com esse dado é possível calcular a velocidade da onda e assim estabelecer a densidade do material. Diversos estudos realizados com o ensaio de VPU mostram que é um método eficaz na detecção de vazios e falhas nas estruturas de concreto.

O método de VPU tem sido cada vez mais utilizado em operações de vistoria e monitoramento de estruturas de concreto, pois o ensaio permite que se meçam e controlem uma série de parâmetros fundamentais para determinar a qualidade do concreto, tanto no laboratório quanto em ensaios de campo. A interpretação dos resultados deste tipo de ensaio, entretanto, necessita ser feita de forma criteriosa e demanda um conhecimento específico dos fatores influentes sobre as leituras. O ensaio de VPU é uma ferramenta importante para avaliação do concreto, sendo que a propriedade do concreto que é mais frequentemente influenciada pelo ensaio é a resistência à compressão (Lorenzi e Silva Filho, 2013). A medida de VPU é influenciada pela densidade do material, e a resistência do material pode ser influenciada pela sua densidade, desta forma torna-se possivel correlacionar a VPU com resistência à compressão. 


\section{FIBRAS}

As fibras são elementos caracterizados por terem uma de suas dimensões muito maior que as outras duas. A inserção delas tem a finalidade de potencializar o comportamento do compósito fazendo com que ocorram mudanças na energia de propagação das trincas. Pode-se dizer desta forma que materiais compósitos são a combinação das propriedades de diferentes elementos resultando em um material com um desempenho superior, quando comparado à performance de cada elemento agindo isoladamente.

A tecnologia de inserção de fibras em concreto já está presente a um bom tempo na indústria da construção, no entanto, estudos para o aperfeiçoamento e dimensionamento de estruturas com fibras são importantes e relevantes. A adição de fibras ao concreto altera suas características mecânicas, como o aumento de tenacidade, resistência à tração e capacidade de absorver impactos, além de alterar suas condições plásticas como a redução da trabalhabilidade (Guimaraes, 2015).

Desta forma, o presente estudo propõe averiguar a influência da adição das fibras de aço e fibras de polipropileno no concreto através do ensaio de VPU, analisando se o comportamento da VPU e da resistência à compressão seguem um determinado padrão.

\section{MATERIAIS E MÉTODOS}

O item aborda o programa experimental da pesquisa, bem como características dos materiais e dos métodos que foram utilizados. Os ensaios foram realizados no Laboratório de Ensaios e Modelos Estruturais (LEME) da Universidade Federal do Rio Grande do Sul (UFRGS).

\subsection{Confecção do concreto}

Para uma melhor distribuição das fibras inseridas no concreto, foram confeccionados blocos de concreto convencional com dimensões de 40 × 20 × $60 \mathrm{~cm}$ de traço 1:2,9:3,6, com uma relação água/cimento de 0,66 e um fck estimado em 25 $\mathrm{MPa}$.

Para a produção do concreto utilizou-se o cimento Portland de alta resistência inicial (CPV-ARI) com massa específica de $3,11 \mathrm{~g} / \mathrm{cm}^{3}$. A areia natural oriunda do Rio Jacuí/RS com módulo de finura de 1,67 , massa específica de $2,52 \mathrm{~g} / \mathrm{cm}^{3} \mathrm{e}$ diâmetro máximo característico de 3,0 mm. Como agregado graúdo, foi utilizada brita basáltica proveniente da região metropolitana de Porto Alegre/RS, com módulo de finura de 7,03, massa específica aparente de 2,75 g/ $\mathrm{cm}^{3}$ e diâmetro máximo de $25 \mathrm{~mm}$.

Os blocos foram moldados de cinco modos distintos: sem adição de fibras (testemunho), com adição de $0,5 \%$ de fibras de aço, com adição de $0,5 \%$ de fibras de polipropileno, com adição de $1,0 \%$ de fibras de aço, com adição de $1,0 \%$ de fibras de polipropileno. As fibras de aço utilizadas possuem $50 \mathrm{~mm}$ de comprimento, com gancho de ancoragem de 5 mm. Já as fibras de polipropileno possuem $50 \mathrm{~mm}$ de comprimento e são corrugadas. As fibras utilizadas estão ilustradas na Figura 1.

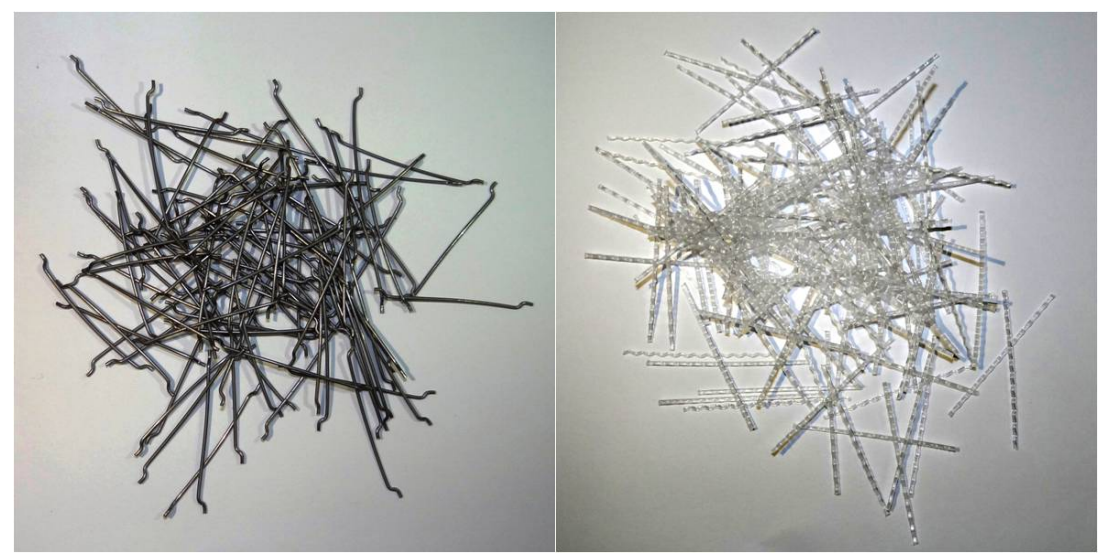

Figura 1 - Fibras de aço e fibras de polipropileno. 


\subsection{Preparação dos corpos de prova}

O período de cura dos blocos foi de 28 dias após a execução do concreto, sendo realizada em Câmera Úmida com temperatura e umidade controlada. Após a cura do concreto, seis corpos de prova foram extraídos de cada bloco e identificados na posição de extração como mostra a Figura 2. Os corpos de prova extraídos foram pesados e medidos a fim de calcular a massa específica de concreto de cada amostra e verificar a influência das fibras adicionadas (Figura 3).
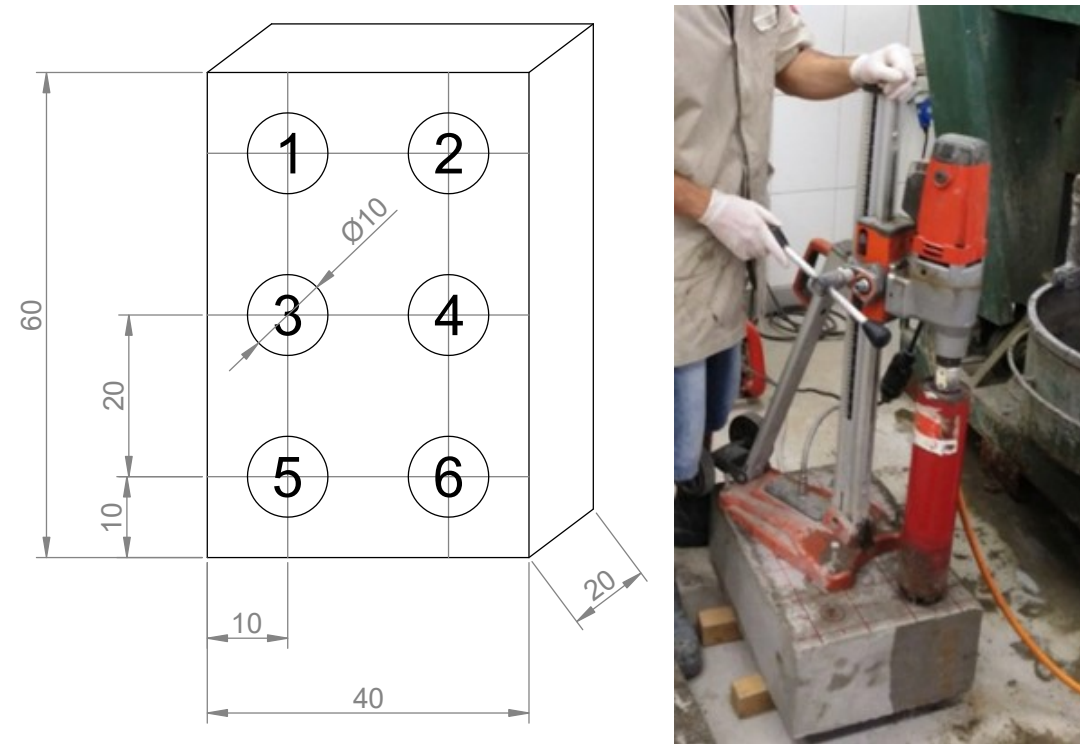

Figura 2 - Esquema de identificação e extração dos corpos de prova.

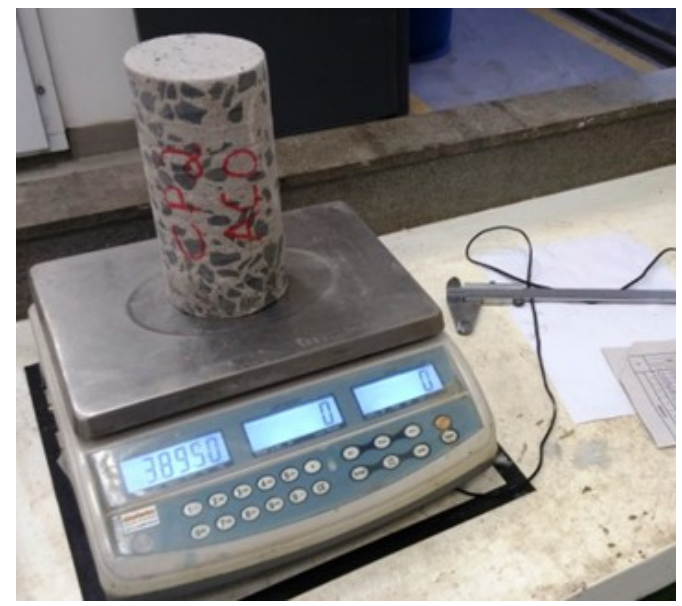

Figura 3 - Pesagem dos corpos de prova.

\subsection{Ensaio de velocidade do pulso ultrassônico (VPU)}

O ensaio de velocidade ultrassônico consiste de um equipamento constituído de dois transdutores de $50 \mathrm{~mm}$ de diâmetro, um emissor e outro receptor, um gerador de pulsos e um registrador de tempo. Esse equipamento emite uma onda através do elemento estudado e com base nas dimensões do corpo de prova e o tempo necessário para que a onda percorra a amostra, foi possível calcular a VPU.

Para a realização dos ensaios o equipamento de teste ultrassônico PROCEQ Pundit Lab foi adotado, bem como foram seguidas todas as recomendações preconizadas na NBR 8802. As superfícies das amostras foram limpas e secas e o método de leitura direta foi utilizado para a realização dos ensaios. De forma a garantir o posicionamento dos transdutores foi utilizado um gabarito de madeira. Em cada corpo de prova foram realizadas três leituras, registrando o 
tempo que a onda demorava para atravessar o concreto. Um valor médio das 3 análises foi utilizado para o cálculo da VPU.

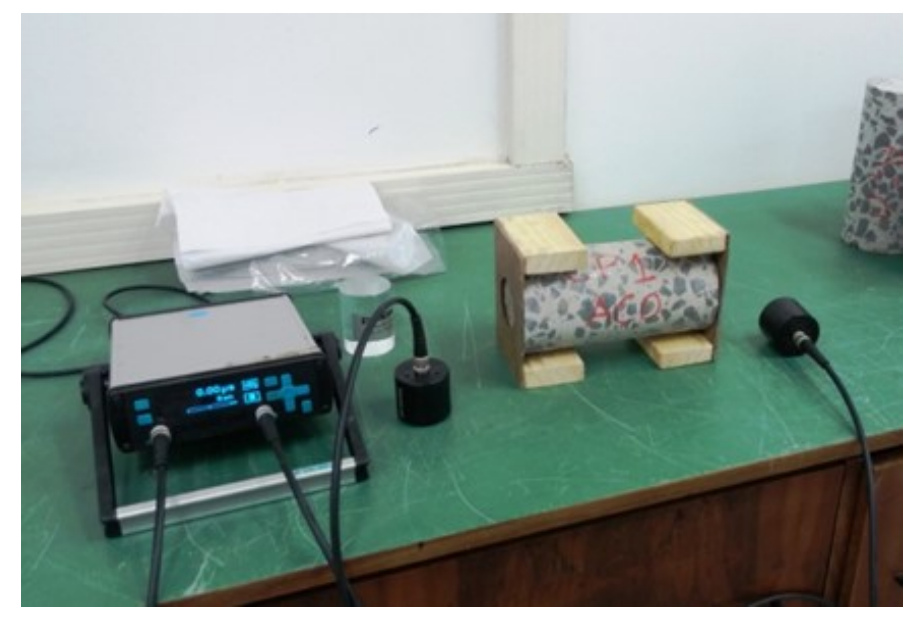

Figura 4 - Ensaio de velocidade do pulso ultrassônico.

\subsection{Ensaio de resistência à compressão axial}

O ensaio de resistência à compressão axial foi realizado seguindo a norma NBR 5739 onde os corpos de prova foram submetidos a uma carga de compressão até sua ruptura, conforme ilustrado na figura 5 . O equipamento utilizado foi uma prensa hidráulica da marca SHIMADZU com capacidade de carga de $2000 \mathrm{kN}$.

Na figura 6 é possível observar a distribuição heterogênea das fibras de aço e polipropileno adicionadas no concreto.

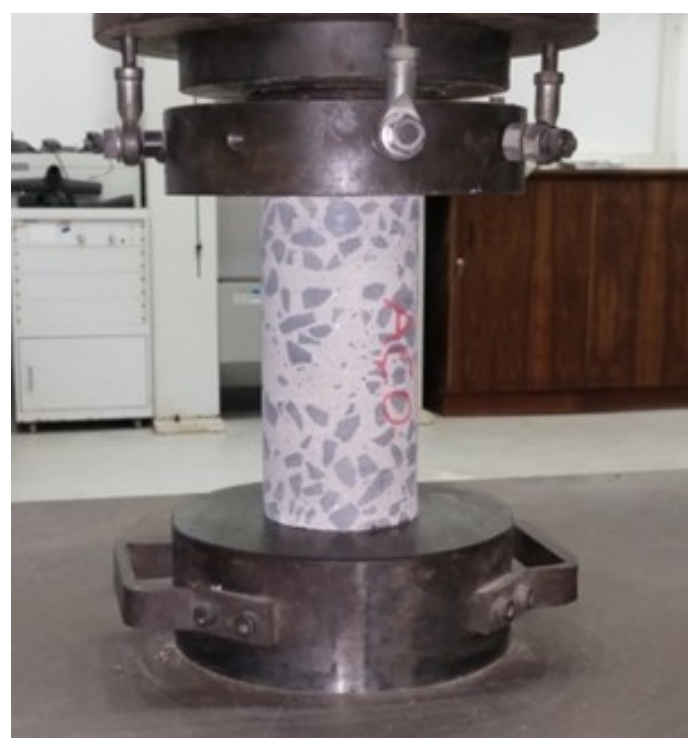

Figura 5 - Ensaio de compressão axial. 

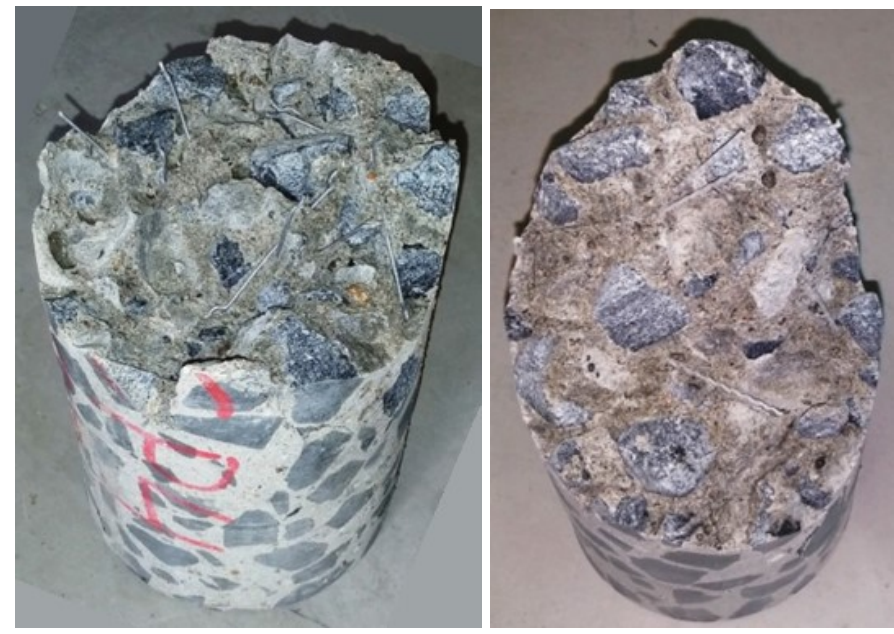

Figura 6 - Corpos de prova de concreto reforçado com fibras de aço e polipropileno rompidos.

\section{ANÁLISE DE RESULTADOS}

\subsection{Massa específica do concreto}

Inicialmente foram analisados os resultados de massa e dimensões dos corpos de prova. Os resultados estão dispostos na Tabela 1 e podem ser visualizados na Figura 7, mostrando a influência das fibras adicionadas no concreto. A adição de fibras de aço teve um aumento mais evidente dado que a densidade do aço é muito maior que a do concreto. Já para a fibra de polipropileno os resultados foram semelhantes ao testemunho, como já era esperado em virtude da baixa densidade do material.

Tabela 1 - Resultados de massa específica em $\mathrm{kg} / \mathrm{m}^{3}$.

\begin{tabular}{|c|c|c|c|c|c|}
\hline \multicolumn{6}{|c|}{ MASSA ESPECÍFICA $\left(\mathrm{kg} / \mathbf{m}^{\mathbf{3}}\right)$} \\
\hline & $\mathbf{0} \%$ & \multicolumn{2}{|c|}{$\mathbf{0 , 5} \%$} & \multicolumn{2}{c|}{$\mathbf{1 , 0} \%$} \\
\hline CP & TESTEMUNHO & POLIPROPILENO & AÇO & POLIPROPILENO & AÇO \\
\hline $\mathbf{1}$ & 2416 & 2416 & 2392 & 2422 & 2490 \\
\hline $\mathbf{2}$ & 2436 & 2422 & 2439 & 2433 & 2500 \\
\hline $\mathbf{3}$ & 2428 & 2422 & 2484 & 2428 & 2506 \\
\hline $\mathbf{4}$ & 2448 & 2440 & 2492 & 2421 & 2496 \\
\hline $\mathbf{5}$ & 2441 & 2458 & 2502 & 2463 & 2526 \\
\hline $\mathbf{6}$ & 2456 & 2465 & 2508 & 2450 & 2533 \\
\hline M & 2438 & 2437 & 2469 & 2436 & 2509 \\
\hline DP & 14 & 21 & 45 & 17 & 17 \\
\hline
\end{tabular}

\subsection{Ensaio de resistência à compressão axial}

Os resultados do ensaio de resistência à compressão axial estão organizados na tabela 2 e mostram o ganho de resistência com a adição das fibras, tanto de aço quanto de polipropileno, em relação ao testemunho.

Contudo este aumento da resistência à compressão não aparenta ser tão significativo (figura 8). Isso decorre em função de que as fibras possuem propriedades de melhor desempenho quando o concreto sofre esforços de tração e cisalhamento. 

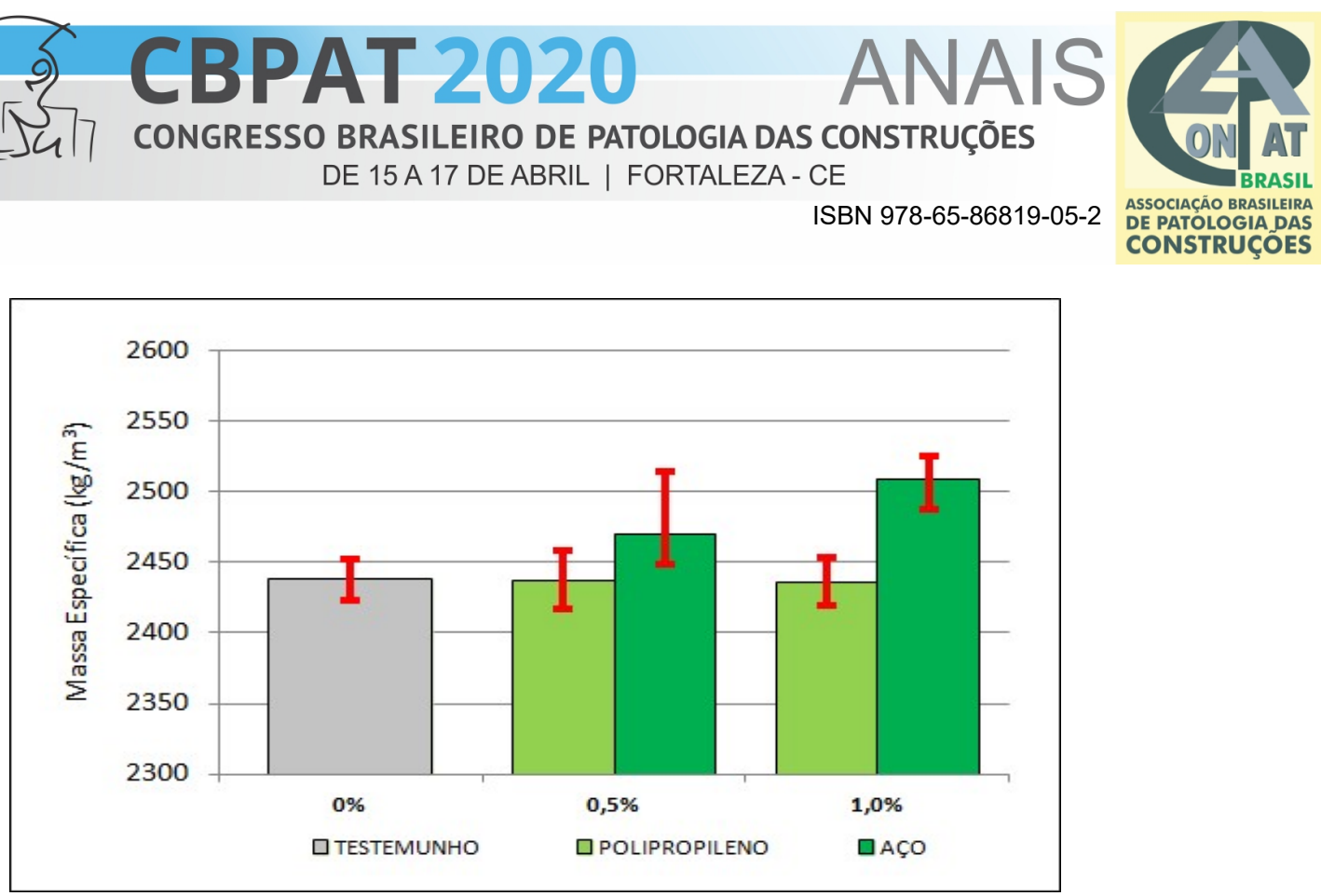

Figura 7 - Comparativo dos resultados de massa específica.

Tabela 2 - Resultados dos ensaios de resistência à compressão axial.

\begin{tabular}{|c|c|c|c|c|c|}
\hline \multicolumn{6}{|c|}{ RESISTÊNCIA (MPa) } \\
\hline & $\mathbf{0} \%$ & \multicolumn{2}{|c|}{$\mathbf{0 , 5} \%$} & \multicolumn{2}{c|}{$\mathbf{1 , 0 \%}$} \\
\hline CP & TESTEMUNHO & POLIPROPILENO & AÇO & POLIPROPILENO & AÇO \\
\hline $\mathbf{1}$ & 22,96 & 23,55 & 27,30 & 26,56 & 30,69 \\
\hline $\mathbf{2}$ & 25,41 & 24,29 & 24,32 & 27,27 & 30,10 \\
\hline $\mathbf{3}$ & 25,29 & 24,75 & 29,74 & 26,00 & 27,32 \\
\hline $\mathbf{4}$ & 24,98 & 24,90 & 30,61 & 25,18 & 27,53 \\
\hline $\mathbf{5}$ & 24,75 & 26,48 & 29,36 & 29,67 & 28,65 \\
\hline $\mathbf{6}$ & 23,25 & 30,30 & 26,92 & 29,84 & 28,39 \\
\hline M & 24,44 & 25,72 & 28,04 & 27,42 & 28,78 \\
\hline DP & 1,07 & 2,45 & 2,32 & 1,93 & 1,36 \\
\hline
\end{tabular}

Neste caso em virtude do tipo de ensaio realizado para se caracterizar os ganhos com a utilização das fibras, o real aumento no comportamento do concreto não está visível através deste ensaio, sendo que o ensaio de compressão diametral será mais representativo.

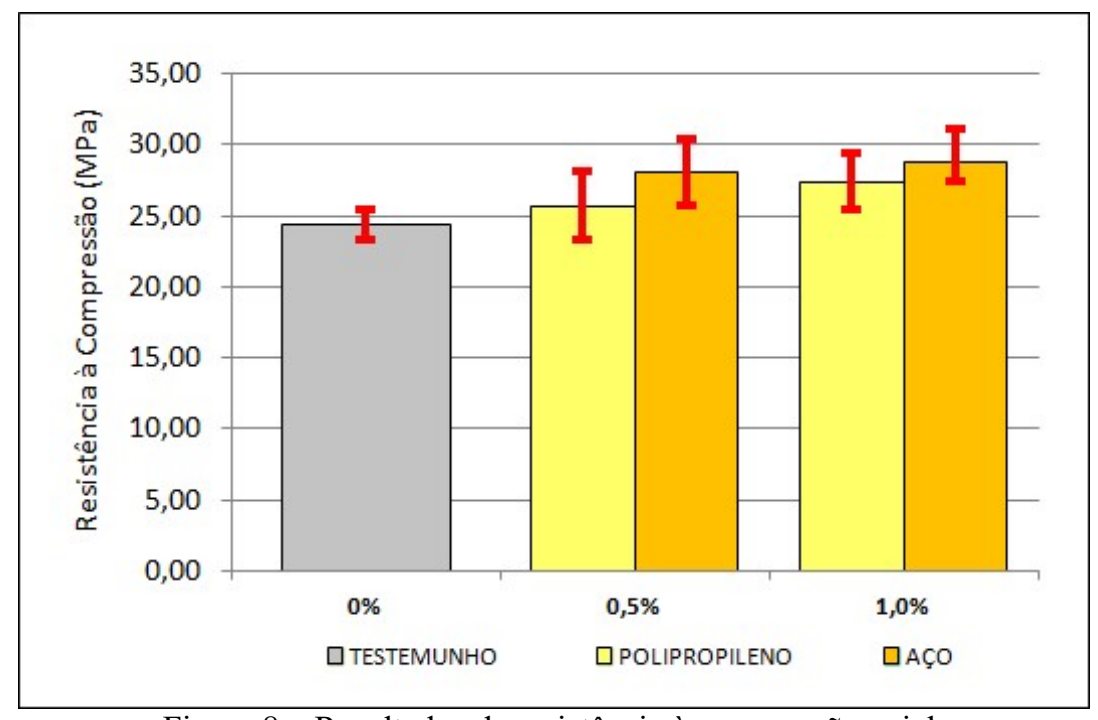

Figura 8 - Resultados de resistência à compressão axial. 


\subsection{Ensaio de velocidade do pulso ultrassônico (VPU)}

Os resultados obtidos no ensaio de VPU estão apresentados na tabela 3. Este ensaio se mostrou bastante sensível à adição das fibras no concreto. Para as fibras de aço, os resultados indicaram um aumento na VPU nos dois teores propostos, como era esperado. Já para a fibra de polipropileno obteve-se em média uma redução na VPU no teor de $0,5 \%$ e um aumento no teor de $1,0 \%$.

Para o caso de polipropileno o comportamento pode estar correlacionado com a densidade da fibra. Analisando-se os dados observa-se que desvio padrão dos concretos reforçados com fibra, tanto de aço quanto de polipropileno, foi maior do que para o concreto testemunho. Isto evidencia que para o caso de concreto com a adição de fibras o comportamento demonstra uma maior dispersão em relação à média.

Tabela 3 - Resultados do ensaio de velocidade do pulso ultrassônico.

\begin{tabular}{|c|c|c|c|c|c|}
\hline \multicolumn{6}{|c|}{ VPU (m/s) } \\
\hline & $\mathbf{0} \%$ & \multicolumn{2}{|c|}{$\mathbf{0 , 5} \%$} & \multicolumn{2}{c|}{$\mathbf{1 , 0 \%}$} \\
\hline CP & TESTEMUNHO & POLIPROPILENO & AÇO & POLIPROPILENO & AÇO \\
\hline $\mathbf{1}$ & 4574 & 4449 & 4449 & 4574 & 4697 \\
\hline $\mathbf{2}$ & 4556 & 4439 & 4508 & 4759 & 4706 \\
\hline $\mathbf{3}$ & 4591 & 4499 & 4692 & 4615 & 4656 \\
\hline $\mathbf{4}$ & 4608 & 4499 & 4721 & 4651 & 4649 \\
\hline $\mathbf{5}$ & 4631 & 4635 & 4695 & 4794 & 4805 \\
\hline $\mathbf{6}$ & 4561 & 4688 & 4657 & 4796 & 4806 \\
\hline M & 4587 & 4535 & 4620 & 4698 & 4720 \\
\hline DP & 29,08 & 102,41 & 113,17 & 97,22 & 70,04 \\
\hline
\end{tabular}

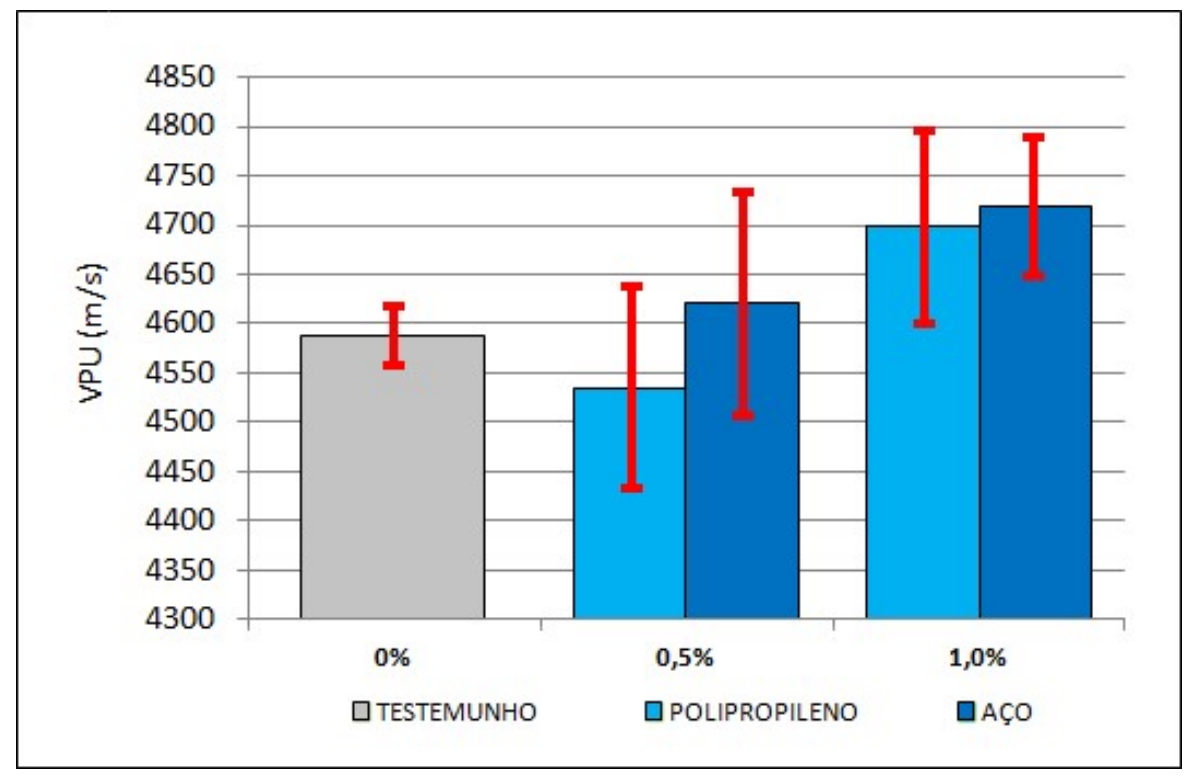

Figura 9 - Resultados do ensaio de velocidade do pulso ultrassônico.

\section{CONCLUSÕES}

Este estudo preliminar indica que tanto a VPU quanto a resistência do concreto são sensíveis a adição de fibras no concreto. A incremento de fibras na matriz do concreto irá alterar as suas propriedades e trazer benefícios ao concreto. A partir da analise dos resultados dos ensaios pode-se fornecer dados importantes a respeito para a tomada de decisão a respeito das condições de estruturas de concreto. Mediante a execução de ensaios de VPU é possível contribuir com o controle da qualidade das estruturas de concreto. 
Sabendo-se que a incorporação de fibras ao concreto está cada vez mais presente nos dias atuais, esta pesquisa buscou analisar sua utilização no concreto e compreender como será a relação existente entre a resistência do concreto, a VPU, o tipo e teor de fibras, bem como analisar se é possível se a técnica de VPU é sensível ao uso de fibras no concreto e pode ser utilizada como ferramenta para estimar a qualidade do concreto com fibras.

\section{REFERÊNCIAS}

Medeiros, A. Estudo de comportamento a fadiga em compressão do concreto com fibras. Tese (Doutorado em Engenharia Civil) - Pontifícia Universidade Católica do Rio de Janeiro, PUC-RJ 2012.

Guimarães, D. Avaliação das Propriedades de Concretos Reforçados com Fibras de Aço para utilização em Pisos Industriais. Dissertação (Mestrado em Engenharia Civil) - Universidade Federal do Rio Grande do Sul. Porto Alegre, UFRGS, 2015 - 184p.

ASSOCIAÇÃO BRASILEIRA DE NORMAS TÉCNICAS. NBR 15530: Fibras de aço para concreto Especificações. Rio de Janeiro, 2013.

ASSOCIAÇÃO BRASILEIRA DE NORMAS TÉCNICAS. NBR 5739: Concreto: ensaio de compressão de corpos de prova cilíndricos. Rio de Janeiro, 2007.

ASSOCIAÇÃO BRASILEIRA DE NORMAS TÉCNICAS. NBR 8802: Concreto endurecido - Determinação da velocidade de propagação de onda ultrassônica. Rio de Janeiro, 2013.

Lorenzi, A.; Silva Filho, L.C.P.; Utilização de redes neurais artificiais para análise de resultados do ensaio de propagação do pulso ultrassônico no concreto, in: XII Congreso Latinoamericano de Patología de la Construcción y XIV Congreso de Control de Calidad en la Construcción CONPAT-Colombia, 2013, Cartagena. Anais do CONPAT 2013. 